\title{
The Contrivance of Mobile Learning: an actor-network perspective on the emergence of a research field
}

\author{
MATHIAS DECUYPERE, MAARTEN SIMONS \& JAN MASSCHELEIN \\ Laboratory for Education and Society, K.U.Leuven, Belgium
}

\begin{abstract}
The ongoing development of mobile devices like cell phones, iPods, PDAs, and so on is seen by an increasing number of educationalists as a chance to focus on a new kind of learning. This mobile learning, as it is called, should enable students to learn while on the move. Rather than giving a genealogy of the use of mobile equipment in education, this article tries to add understanding to the processes that made possible the emergence of this new research domain. In doing this, the authors use one specific theoretical approach, actor-network theory, which will lead to a profound elaboration of the processes involved in new, emerging research fields.
\end{abstract}

\section{Introduction}

Rapid and vast technological changes have made mobile learning, also called m-learning, a hot topic in recent years. Considered as a part of e-learning, m-learning allows learning by means of mobile devices (cell phones, iPods, etc.). This particular kind of learning has recently attracted the attention of many scholars. There has been a steep rise of mobile learning in educational research (see, for instance, recent books from Ally [2009] and Pachler [2009]), with research that investigates multifarious kinds of subject matter, from science (Sims Parr et al, 2004) over butterfly watching (Chen et al, 2005) to the arts (Naismith \& Smith, 2009). At present, different theories of learning can be recognized, from a more behaviouristic (e.g. Geddes, 2004) to a more constructivist (e.g. Zurita \& Nussbaum, 2004) and socio-constructivist (e.g. Roschelle et al, n.d.) perspective. All in all, the research field on mobile learning is relatively new and not fully developed yet (Traxler, 2009). This newness and prematurity offers interesting and promising perspectives for the study of emerging research fields. Indeed, the surfacing of mobile learning and its corresponding scientific study enable a thorough investigation of occurring processes in the formation of new research domains.

In what follows, we are particularly interested in such processes. This interest is, however, not new: in the past a versatile range of approaches and theories have been developed that one way or the other try to conceptualize processes at play in science, and more particularly in what could be called 'science in the making': from paradigmatic shifts (Kuhn, Popper) to neo-Marxist-inspired schools that deal with criticising social aspects and consequences of scientific discoveries (Critical Theory; e.g. Horkheimer, Habermas) and related theories that try to debunk mechanisms which have as their main purpose the perpetuation of the ruling class (e.g. Althusser) to theories that stress the supremacy of masculine ideas and thoughts (e.g. Butler, Haraway). However, it is not our purpose to elaborate on most of these issues here. Rather, in this article we are more particularly taking up a poststructuralist-oriented approach in the sense that we will not deal with overarching and determining structures (male, ruling class, etc.) that make up the (mobile learning) research field. Specifically, the point of approach in this article is socio-technical and can be denominated as actor-network theory, which has roughly speaking as its main purpose the 
description of forming networks mutually constituted by 'active actors'. Our approach here, then, is neither instructional (Ally, 2009), sociological (Castells et al., 2007), nor philosophical (Nyíri, 2002). For instance, we are not interested here in how mobile devices deliver their content, nor in the way and extent to which they contribute to the learning of students. Rather, in this article, we wish to focus on the emergence of this relatively new research domain, and more particularly on the processes and mechanisms that assist in assembling and constituting this new domain: we are interested in the processes that help make mobile learning a distinct research domain, separating it from other domains of educational research. The key question of this article can hence be formulated as follows: Which processes make mobile devices and mobile learning part and parcel of the educational research field? In what follows, we will first of all briefly introduce actor-network theory. That being done, we will focus on the research domain 'mobile learning' through the lens of this theory. By studying one concrete example, we will make clear that different concepts of actornetwork theory can reveal some patterns and a way of looking that can be useful for other, more, or different examples in the field of m-learning in particular and for other (emerging) research fields in general.

\section{Actor-Network Theory}

Actor-network theory (ANT) emerged in the field of science and technology studies (STS) and soon became an important player in this STS field. Initially, the main focus was on the study of 'science in the making' - that is, on the discovery of scientific facts in laboratories. Once discovered, facts are spread within scientific communities. Those communities can accept or reject those facts, but once accepted, the facts become part of broader theories and become in their turn a basis for other scientific research. However, those facts and theories are not merely objective - and hence they are not just discovered as if the outside world was waiting for them to be seen by human eyes - but socially constructed as well. In the creation of a scientific theory, this social construction is, according to ANT, as important as the laboratory work undertaken (Latour \& Woolgar, 1986; Latour, 1987). ANT is, however, not only an approach to science. It is also (amongst other things) a specific approach towards technology. As far as technology is concerned, the same analysis applies: ANT claims that in technology it is not only objects that play a role - social construction does as well. Indeed, technology is at least in part socially constructed. This implies concretely that, according to ANT, many relations and entities (be they scientific, technological or social) can be described not only as human, but also as material and semiotic: ANT sets forth 'the enactment of materially and discursively heterogeneous relations that produce and reshuffle all kinds of actors', which allows human and non-human entities to take up their form and acquire their attributes as a result of their (material and discursive) relations with other entities (Law, 1999, p. 3; 2007, p. 2). A main focus of ANT, then, is on tracing such relations and on following the paths these relations leave behind. This is why ANT is usually not regarded as a theory but rather as a method that helps to trace associations. Such tracing can be done by analysing emerging assemblages of associations in the interplay between specific actions of human actors and non-human devices in their material/immaterial environment (Callon, 1986; Latour, 1999a, 2005 [see below]).

In what follows, we will try to show how ANT can be used in a descriptive way with regard to the research field of mobile learning. In other words, the present article will trace associations that are coming to the fore in this research domain. In line with core principles of ANT (Latour, 1999a, 2005), we will show that associations incorporate more than human(-made) associations alone. In particular, we will show that some non-human entities/actors play a decisive role as well in the formation of new research domains (taking the case of mobile learning as one particular example). Hence, by means of ANT we will demonstrate (1) that emerging research fields are always constituted by assemblages of associations, involving the human as well as the non-human; and (2) that the formation of such assemblages is characterized by specific processes and actions. For instance, claims like 'mobile devices can be used as instruments for learning' are not just facts as such. A lot of processes are needed to make such claims, and a lot of work has to be done before such claims can be made at all. Let us disclose some of those processes, and some of the work. 


\section{A Particular Mobile Learning Study, a Particular Mobile Learning Device}

ANT has always held as one of its main tenets that the object of study has to be as concrete as possible. Avoiding general statements should enable relations and associations to be traced more profoundly (Latour, 2005). We will try to stay close to this aim. In order to be as concrete as possible, we take on mobile learning study as a particular example. The study we will focus on here is a well-known one, if not one of the most known in the mobile learning field - namely, a study by Chen et al (2003), the purpose of which was the development of 'a mobile learning system for scaffolding students $[$ sic] learning about bird-watching' (p. 347). The mobile device used was a Personal Digital Assistant (PDA) - a device we can nowadays consider as a predecessor of the smart phone, as smart phones contain besides PDA functionalities a lot of other properties. Smart phones combine mobile phone capability with a PDA, camera, mass storage, Internet access, MP3 player, etc., in one compact system. This type of mobile phones is becoming increasingly popular: in February 2009, 33\% of all purchased mobile phones were smart phones. The cell phone, and especially the smart phone, seems, according to some scholars, particularly well equipped to contribute to students' mobile learning (Corbeil \& Valdes-Corbeil, 2007; Motiwalla, 2007; Tsirulnik, 2009). The study of Chen et al (2003) is one of the earlier studies that explored the educational capacities of a mobile device, which makes it particularly interesting for the study of the emergence of the mobile-learning research domain. A short overview of the article is given in the next paragraph.

The study of Chen et al (2003) starts with an introduction. In this introduction, the authors sum up some characteristics of mobile learning environments, explain the concept of scaffolding ('the interactive support that instructors, or more skilful peers, offer learners to bridge the gap between their current skill levels and a desired skill level' [p. 348]), and give some technical details about the PDA and its software. The next section is a review of the available literature on scaffolding that served as a basis for the development of the software needed. This section also points to the finding that mobile learning environments are particularly suited for giving learner support in the form of scaffolding. On the basis of this finding, the authors remark that their mobile bird-watching system contains all the components that are deemed necessary in giving effective scaffolding support. The third section explains the concrete setting, the specifics of the software and the concrete data-collecting procedures. The authors provide the reader with information about the technical objects (PDA, wireless network cards, digital video camera), the protocols used (routing protocols, Wi-Fi protocols, etc.) and the interface available for the learners on their PDA software, compatible with effective scaffolding techniques. Data collection is based on a 'pretest middle test - posttest design': a test before the experiment to assess prior knowledge, a test during the experimental $\mathrm{m}$-learning phase, the purpose of which was to guide students' attention, and a posttest, the purpose of which was to measure what was learned. The fourth section gives some methodological details: the research design (three phases of experiments, each time including a corresponding control group that did not use a PDA but instead a more traditional guidebook), and an overview of the participants, of the testing moments and of the experimental design (focusing on the content of the three tests undertaken). The fifth section informs the reader of the results obtained. Those results are quantitative, obtained by means of analysis of conducted $t$-tests, probability estimates, multi-level analyses, etc. Chen et al noticed increased learning gain for the students in the PDA group. The article ends with a conclusion (improved learning, 'above and beyond what would normally be expected' [p. 358]), an acknowledgement and a reference list.

\section{Actors and Networks}

This summary enables us to conduct an analysis of the actors in play and the associations they form, as well as to focus on the assembling processes that help in constituting a new and distinct research field. According to actor-network theory, actors can literally be anything: humans, devices, texts, concepts, and so on. The only requirement to be designated as an actor is being the originator or perpetuator of a certain action. Indeed, actors act. Entities that do not act and do not leave any traces behind can hardly be considered actors at all. Actors thus have to possess agency, and there is no (initial) differentiation between the human and the material as point of analysis (Murdoch, 1997; Latour, 2005). What, then, does this concretely imply for the study we described 
above? It implies foremost that 'participants' and 'researchers' cannot be seen as the only actors who constituted this study, for they are not the only sources of action (they are not the only entities that leave traces behind). In what follows, we provide a point of view incorporating these and other actors that emerge through an ANT focus (drawing on a more detailed example from Callon [1986]):

Chen, Kao and Sheu: before those researchers conducted and reported their study, they were already in possession of a lot of information/knowledge. They knew that mobile devices and mobile learning environments are characterized by some features, and they knew as well that the pedagogical principle of scaffolding had been investigated quite extensively already. What was not known, however, was whether the use of scaffolding in mobile learning environments would produce an additional learning gain in comparison with classical mobile learning environments (without scaffolding). Their goal was to advance available knowledge in this respect, specifically pointed at bird-watching. In order to do this, they based their research on available scientific knowledge - for example, on statistical models that already had proven their worth and on already established evidence regarding scaffolding. Finally, it is this group of three researchers that produced the written record of the study conducted (the article).

The participants: the written record could not be produced by the three researchers-authors alone. They needed to draw on the scientific knowledge base on the one hand, but on the other hand they needed participants for the study as well. The traces those participants leave behind are in a certain respect rather modest, for they are made completely anonymous by the three authors. We only know that they are students from three elementary Taiwanese schools that are situated close to a bird-watching site (p. 355). However, their contribution is in another respect immensely big: without those students, there would not be a study at all!

The mobile devices: what we stated about the participants applies equally to the mobile devices used. Without them, the study would not be possible. They are supposed to make m-learning possible, especially when the technique of scaffolding is integrated into the software of the PDA. The PDAs are at the core of the study: used by the participants, they provide the data that will be used by the researchers in order to produce a scientific account.

The scientific community: the scientific community itself can be seen as a fourth actor. This community is always present. It shapes the introduction of the paper (anchoring the research conducted to already proven facts), the theoretical framework (coupling mobile devices with an instructional technique), the data collection (in accordance with valid and reliable statistical methods) and the conclusion (showing the community that the research base has advanced due to the study). Furthermore, the community constitutes requirements in terms of the format and layout of the paper. Indeed, the scientific community is present in the journal the authors submit their article to as well. Some requirements in this respect are: grounding (providing a full examination of the literature, and refereeing to key publications), originality (making a substantially new contribution), clarity (explanation and justification of research methods) and economy (organising the article with suitable headings and without superfluous figures/tables) (JCAL, 2006).

Thus far, we have four actors: the three researchers, the participants, the mobile devices and the scientific community. This list is, however, neither exclusive nor complete: other actors (e.g. the mobile equipment industry, new journals and research methods) play their part in the emergence of a new research field as well. As the research field develops, more and more actors will come into play, making connections with already established and new emerging actors. This analysis, thus, could be taken further as the research field unfolds itself. Another possibility, furthermore, could be to investigate the unfolding associations surrounding the study of Chen et al (2003): it would be interesting to analyse how this article is becoming an essential brick (or foundation) in the construction of the research field on mobile learning. Limiting ourselves, though, to this one 'landmark' article and discussing only the four actors mentioned above, it is important to stress that ANT is not only a guide in the denomination of actors, it is also an argument for fathoming interrelations between actors in terms of networks. Networks as conceived by ANT are, however, not conceptualized in a classical, node-connecting way. In common understanding, networks (e.g. the Internet) are considered as connected nodes that provide mere transport of information between node A and node B. The very purpose of networks in this sense is to transport from one node to the other as accurately as possible (Latour, 2005). 
That is not, however, the meaning of the concept in ANT. In ANT, the notion of network refers to the distribution of action among all actors, and its core property is the prevalence of internal transformations. These transformations do something, and cannot be limited to mere transport with unmediated access where no deformation takes place. The transformational character of networks implies that actor-networks inaugurate multiple associations and translations: actors get connected, but their bonds are also prone to change, to weakening and to growth. Stated otherwise, connections and associations are always provisional and can always change (Latour, 1999a,b, 2005). Can we, in an exemplary way for the emerging m-learning field, depict a network in this sense in Chen et al's (2003) study? To answer this question, we will need to put into position some more concepts and processes, starting with the notion of translation. Translation has to be understood as the (de-/re-)formation of a network. According to Callon (1986), translation consists of four moments, which we will discuss below. Chen et al (2003) is only one particular example in this respect - similar analyses could be conducted with many other studies.

\section{Translation, or Putting Together the Study}

The study of Chen et al (2003) starts with a research question posed by the researchers which they will attempt to resolve. It does not suffice, however, to just pose the question. The question has to be embedded in the field of already existing scientific evidence in order to obtain a solid problematization. Without this embeddedness, the question would stand alone and it would consequently turn out to be rather hard to obtain legitimacy in the eyes of the scientific community. Therefore, Chen et al stabilized the identity and properties of the actors mentioned above: (1) they themselves were disinterested researchers in search of some facts (and, for example, not people who put into play their own personal biases); (2) the mobile device used was put together with some technological features, protocols and interfaces (and not with some other ones); (3) the participants were Taiwanese students (and not of another nationality); (4) the community of researchers was conceived of as a player in the scientific field that could provide relevant information regarding studies of mobile learning and scaffolding, acting as a source of inspiration and sound basis of legitimization (and not as, for example, a group whose opinions should be criticized). In this way, the three researchers act as what Callon (1986) has called an obligatory passage point: they become indispensable in the network they are putting together themselves. They are what holds the mobile devices (to be regarded as mobile learning devices if Chen et al's study delivers the expected results), the participants (doing only what they are assigned to do, but crucial in the development of the results) and the scientific community (hoping to build a sounder knowledge base) together.

Once the situation is problematized sufficiently, a phase of interessement (i.e. processes that seek to lock actors into roles proposed by the three researchers) puts all the described actors into place. (1) After the stabilising mechanisms in the process of problematization, the actors in question are extracted from their context in the phase of interessement. This phase is conducted by Chen et al, who will try to delineate important characteristics of the other actors. This work immediately delineates their own role as well: they are researchers who try to gain scientific understanding by means of a clear delineation of each actor. (2) The participants are put in a field-experimental setting, which makes sure that as long as the experiment lasts, the participants are only participants: at the moment of the experiment, because of the very nature of an experiment, they are not considered as youngsters with emotions, with family and friends, and so on. They are only students who may be able to learn better with a PDA. (3) The same applies for this PDA: the PDA is used here only as a learning device, not, for example, as a device for personal pleasure nor for the setting of one's agenda. (4) The role of the scientific community is lucid as well: for instance, it serves as a sound basis and legitimization for the establishment of the conceptual framework and for the way the article is written (e.g. in the form of journal guidelines).

Interessement has the purpose of leading to enrolment - that is, to actual alliances. The scientific community will not accept the study of the three researchers if it is not considered to build on (that is, form alliances with) previous research and if it is not conducted in a valid and reliable way (this is also mentioned explicitly in the author guidelines of the journal - see above). Therefore, the researchers do everything they can to anchor their study in the already-built 
knowledge base (refereeing extensively in the introduction, trying to extend the already established concept of scaffolding to the field of m-learning, using statistical models that have proven their efficiency in the past and that are recognized as part of conducting a good methodology, etc.). And as weird as it may sound, the researchers even have to negotiate and form alliances with the mobile device: if the researchers effectively want to enrol the PDA, those PDAs have to be able to contain characteristics that enable mobile learning. This negotiating is, in fact, a negotiation of the researchers with the possibilities and potential alliances of the merger of hard- and software: Can you contain scaffolding elements? Do we have to build protocols and put in some extra hardware so you are able to do this? Which information do you need to have stocked on your hard drive so that our participants can easily retrieve what they want to find, and how does it need to be composed? The participants, in their turn, are left aside. They have to wait until everything else is in place before they can be immersed in the experiment and then be tested. They only have to do what the three researchers tell them to do; the only thing that counts concerning the participants is, indeed, that they participate (which is, however, a crucial and important action).

A last phase has to be completed yet in order to finish the process of translation: the allies must be mobilized, meaning that bonds are forged with actors who are no part of the initial actornetwork. This last phase is necessary because in either stage of the translation process, the number of entities is few. Only 86 participants, only half of whom (the experimental group) received a PDA: the numbers are sparse. This makes it very important that the entities included in the study are considered to be representative. If not, the study could fail eventually - it might not be recognized as generalizable scientific research. However, although not put explicitly in their text, Chen et al might have had the purpose of generalizing their findings to a larger field (that is, a population) of students. Plus, and equally importantly, there probably is some purpose of generalizing the findings to other PDAs, other smart phones, other mobile learning devices as well. To conclude, even in the case of the scientific community it is the case that 'a few individuals have been interested in the name of the masses they represent' (Callon, 1986, p. 215). Indeed, convincing the total scientific community is way too hard, if only because only a few colleagues (probably in the field of learning and instruction) will have read the publication of Chen et al. It is almost impossible to have all educationalists read this very article, let alone convince all educationalists with the argumentation of the three researchers. Inevitably, some of them would disagree with it. However, all of this does not matter much. What matters is that the colleagues who read this very article function as spokespeople for the scientific community as a whole. They represent, and thus speak in the name of, all researchers interested in this topic. Hence, what we can notice here is a mechanism by which the large population of students, the considerable quantity of mobile devices and the numerous members of the scientific community are all represented by only three researchers. But how is this done? How is it possible that so many individuals and entities are reduced to a representation of three?

\section{Inscription, or Being Able to Bring Results to the Fore}

The learning effectiveness of mobile devices is by itself a concept too comprehensive to be operationalized adequately. Therefore, it is broadly recognized that researchers should limit the scope of their study: a lot of research, for instance, studies one particular kind of mobile device, and not the total mass of available technologies. Chen et al were no exception in this regard: they let PDAs speak for the total group of mobile devices. That being done, the work had only started. The actor (mobile devices) had to be reassembled in order to obtain an answer to the question, Do mobile devices with integrated scaffolding support contribute to mobile learning over and above classical instruction? As we already indicated, scaffolding was made possible by designing a specific birdwatching interface with integrated scaffolding support. Furthermore, an interesting feature of the PDA is its potentiality for conducting electronic tests. This allows data processing to become fairly easy, for the obtained answers can be quickly encoded into a software program. These codes, in their turn, are quantitatively analysed with the statistical tools already described. Calculations make the final transformation of the data possible: tables, diagrams, curves, etc. make it possible not only that the two conditions (experimental vs. control group) can be compared at a glance, but also that the whole experiment, accurately conducted over a considerable period of time, is made 
transparent and accessible for the community of researchers who were not there when the experiment itself was conducted. This allows the study of Chen et al to become a potential reference for this community. The merger of participants and PDAs is thus transformed as follows:

Mobile devices - > PDAs - $>$ interface $->$ tests $->$ data -> calculations - $>$ numbers, graphs,

diagrams -> accessibility for scientific community

The process we described here is referred to in ANT as inscription: the transformation of a certain reality into written, pictorial, graph-like, etc. accounts. In the process of inscription, the materiality of the process gets deleted and transparency and comparability are the common outcome (Law, 2004). The apparatuses that produce such inscription are called inscription devices:

An inscription device is any item of apparatus or particular configuration of such items which can transform a material substance into a figure or a diagram which is directly usable. (Latour $\&$ Woolgar, 1986, p. 51)

What happens in the process of inscription is not only a deletion of the materiality of the process and a facilitated comparability; the reality in which the study took place transforms in the text of the three researchers into an inscribed reality: the inscription devices (e.g. data-processing software to produce the data, and a word processor for the actual writing of the publication) in a certain sense construct the reality we can only read about now in the publication (Latour, 1987; Law, 2004). The diagrams, figures and graphs determine what other researchers can analyse, for they were not there when the experiment was conducted. The particular type of smart phone (PDA) also determines which results were obtained. Studying data quantitatively also inscribes, and constructs the reality in a particular way. These are just a couple of examples to make clear that inscriptions are not mere neutral tools. They determine what can be read and what cannot, what can be compared and what cannot, what can be considered as (new) knowledge and what cannot. They also make it possible for the three researchers themselves to discuss the diagrams, figures and graphs. In discussing such inscriptions, Chen et al actually discuss the fate of many other actors that remain silent after the period of measurement is completed: other mobile devices (other types of PDAs or smart phones) and other students (non-Taiwanese, for instance). Furthermore, as the study is published, other researchers can refer to Chen et al. This, in its turn, is another inscription: the study of the three researchers is condensed in the phrase 'Chen et al, 2003'. The summarization of the total study in this tiny phrase contributes to processes of 'irreversibility' and 'black-boxing', two processes we will discuss below.

\section{Irreversibility, or Becoming a Nexus in a New Emerging Research Field}

Naturally, the study elaborated upon in the present article is only one particular (albeit influential) example of an expanding research domain. As the research field on mobile learning grows, more and more (groups of) researchers conduct and publish the results of their studies. Likewise, more and more technological advances are achieved. PDAs are being replaced by smart phones, but the research that has been done on PDAs remains open for exploration. And so it happens that Chen et al's (2003) study is cited more and more in mobile learning studies. Moreover, more and more theories and definitions of mobile learning are put forward by different researchers (see Traxler, 2007). All of this contributes to making the actor network durable. In the meantime, mobile learning gradually leaves the academic world and is also becoming part and parcel of concrete educative practices and applications. Handbooks for educators and trainers are already available (e.g. Kukulska-Hulme \& Traxler, 2005), m-learning is already applied in a lot of universities, etc. In other words: the actor-network is becoming irreversible. According to Callon (1986, 1991), irreversibility signifies the ever-growing harshness of going back to a former network state. New connections and associations made by mobile learning research shape and determine subsequent translations: it is becoming extremely difficult not to recognize mobile learning as part of the possibilities of broader educational practices (i.e. as a social element) and as part of the possibilities of mobile devices (i.e. as a technical element), notwithstanding the fact that controversies can still arise and compete with the new bounds that are forming and aligning. 


\section{Into the Black Box, or the Fusion of Actor Networks}

With the actor-network becoming more and more irreversible, the way is paved for a new process, termed by Latour (1987) as 'black boxing'. Already in the introduction of their article, the three researchers describe mobile learning as something that is not uncertain or prone to controversy, but as something that is possible:

With the aid of wireless communication technology, educational practice can be embedded into mobile life without wire-based communication. With the trend of the educational media becoming more mobilised, portable, and individualised, the learning form is being changed dramatically. (Chen et al, 2003, p. 347)

If we take a closer look at these two sentences, what is striking is that references are absent. We already pointed to the importance of refereeing, and more precisely to the importance of the scientific community. It would thus be only familiar and reasonable to refer to some authors when making these statements. But that is exactly what this is all about: what Chen et al do here is not at all crooked intellectual practice, for they envisage the statements made in those two sentences as (already) established facts. The three researchers, and with them the scientific community, consider it as a fact that 'educational practice can be embedded into mobile life', that educational media are becoming more 'mobilised, portable, and individualised'. Hence, it is not necessary any more to prove that the statements made here are factual proven givens: they are just taken to be facts. In a similar vein, the study of Chen et al itself seems to be considered as a fact nowadays: when referred to, Chen et al's study (2003) seems to incorporate facts such as 'mobile learning enables the conditions for authentic learning to be met' (Kukulska-Hume et al, 2007, p. 55) and 'mobile technologies are helpful on field-trip-based and outdoor learning' (Lai et al, 2007, p. 327). With such statements, the work and investigation of Chen et al (2003) seem to disappear into the background; the results of the study and their interpretation by other researchers, who treat those results as obtained facts, are what count most and are what is consequently placed in the foreground. This 'disappearing-into-the-background' is what is meant by the term black box: 'a black box contains that which no longer needs to be considered, those things whose contents have become a matter of indifference' (Callon $\&$ Latour, 1981, p. 284). However, we do not want to put forward here that all features and properties of m-learning have become a matter of indifference. The emerging research field on mobile learning shows this is simply not the case. Rather, the very fact that people can learn while being mobile and by means of mobile devices is the black box here: m-learning as a prevalent and factual phenomenon. It serves as the unshakable basis for more uncertain theories (Harman, 2009, pp. 36-37) - such more uncertain theories being, for instance, that scaffolding is possible in a mobile learning setting. Thus, the black box 'mobile learning is possible' is so stable and so certain that it can be treated as a fact. It is so embedded and taken for granted that it is not necessary any more to point to the processes that were needed in order to close the box. It is not any longer required to refer to studies and experiments that have actually proven that people can adapt successfully to mobile learning. People just can. Black boxing thus provides mobile learning studies with their legitimacy, explains their manifestation in the field of instructional research, and allows - combined with the other processes that are reported here - a profound understanding of the processes at play in the establishment of a new research domain.

\section{Conclusion}

This article has tried, by means of actor-network theory, to introduce a relatively uncommon conception of the emergence of a new scientific domain in mobile studies, which may lead researchers to a different understanding of the mechanisms driving the ongoing construction of the 'mobile-learning field' in particular and the establishment of 'emerging research fields' in general. In this article, we highlighted important actors and tried to elucidate processes that play a role in the establishment of a research field on mobile learning. We did this by taking one study (Chen et al, 2003) as a particular case and as a point of departure. Even though we limited ourselves to the discussing of one particular article, different (groups of) human and non-human actors could be discerned. One argument in this article was that one can only take a look at effects a particular study generates if one investigates the connections and associations that are linked to a study. This 
point of view enabled us to highlight some processes that played their part in the emergence of a new research field - namely, translation, inscription, irreversibility and black boxing. A consequence of such processes is that actors never stand alone; they engage in processes of translation with more established actors and compose what we have called here an actor-network. This implies, moreover, that technological equipment should not only be thought of in terms of what it does and does not allow/afford. Technological equipment should also be considered as consisting of devices that construct a particular kind of reality by means of inscription. Therefore, we could think of technological equipment in research activities as socio-technical devices: devices that let us think of research in terms of a distribution between the scholar and his or her situation, for the device (situated in an environment) is an active co-constructer of the research taking place (Callon et al, 2002). However, such divisions should be handled with caution. This article abstained from traditional divisions between what is global and what is local, what is structure and what is agency, what is macro and what is micro. We did not argue, for instance, that research is conducted in a world where technological equipment is ubiquitous (global, structure, macro), nor that scholars are embedded in such kind of world (local, agency, micro). Indeed, ANT only allows one to take a look at the traces actors leave behind, not to make assumptions about the kind of world we live in nowadays. Those assumptions can, of course, be right, but if they are - and more precisely if they matter - the method of ANT should enable one to find them in the field of actornetworks. The actor we typified as the scientific community, for instance, can be regarded as a contextual given that makes connections - traces - with a particular reality of a particular study.

The focus on one particular study means that a lot of work remains open for exploration. A more profound investigation could take into account other studies, which would be a fruitful guideline for further research. Another possible similar direction for further research could be to conduct an actor-network study involving the whole field of mobile learning - that is, looking for more associations, translations, etc. than we have done here due to space restrictions (but see for an example McBride, 2003).

In sum, the field of mobile learning has exploded in the last couple of years. More and more researchers are investigating characteristics and particularities of mobile learning. ANT helps us realize that neither purely technical, nor purely social, nor purely instructional elements are involved, but that all these are interwoven in mutual relationships. The challenge for researchers in this and other emerging scientific fields is to understand all of these relationships: none of the actors stands alone. This could, in its turn, make the characteristic properties of each of the actors and their interactions with other (human and non-human) actors clearer.

\section{References}

Ally, M. (Ed.) (2009) Mobile Learning: transforming the delivery of education and training. Edmonton: AU Press.

Callon, M. (1986) Some Elements of a Sociology of Translation: domestication of the scallops and the fishermen of St Brieuc bay, in J. Law (Ed.) Power, Action and Belief: a new sociology of knowledge, pp. 196-233. London: Routledge \& Kegan Paul.

Callon, M. (1991) Techno-economic Networks and Irreversibility, in J. Law (Ed.) A Sociology of Monsters: essays on power, technology and domination, pp. 132-161. London and New York: Routledge.

Callon, M. \& Latour, B. (1981) Unscrewing the Big Leviathan: how actors macro-structure reality and how sociologists help them to do so, in K. Knorr-Cetina \& A.V. Cicourel (Eds) Advances in Social Theory and Methodology: toward an integration of micro- and macro-sociologies, pp. 277-303. London: Routledge \& Kegan Paul.

Callon, M., Méadel, C. \& Rabeharisoa, V. (2002) The Economy of Qualities, Economy and Society, 31(2), 194-217. http: / / dx.doi.org/10.1080/03085140220123126

Castells, M., Fernández-Ardèvol, M., Qiu, J.L. \& Sey, A. (2007) Mobile Communication and Society: a global perspective. Cambridge, MA and London: MIT Press.

Chen, Y., Kao, T. \& Sheu, J. (2003) A Mobile Learning System for Scaffolding Bird Watching Learning, Journal of Computer Assisted Learning, 19, 347-359. http: / / dx.doi.org/10.1046/j.0266-4909.2003.00036.x

Chen, Y., Kao, T. \& Sheu, J. (2005) Realizing Outdoor Independent Learning with a Butterfly-watching Mobile Learning System, Journal of Educational Computing Research, 33(4), 395-417.

http: / / dx.doi.org/ 10.2190/0PAB-HRN9-PJ9K-DY0C 
Corbeil, J.R. \& Valdes-Corbeil, M.E. (2007) Are You Ready for Mobile Learning? Educause Quarterly, 30(2), 51-58.

Geddes, S.J. (2004) Mobile Learning in the 21st Century: benefits for learners. http:/ / knowledgetree.flexiblelearning.net.au/edition06/download/geddes.pdf

Harman, G. (2009) Prince of Networks: Bruno Latour and metaphysics. Melbourne: Re.press.

Journal of Computer Assisted Learning (JCAL) (2006) Guidelines for Authors. http://jcal.info/guidelines_for_authors/index.htm

Kukulska-Hulme, A. \& Traxler, J. (Eds) (2005) Mobile Learning: a handbook for educators and trainers. London: Routledge.

Kukulska-Hulme, A., Traxler, J. \& Pettit, J. (2007) Designed and User-Generated Activity in the Mobile Age, Journal of Learning Design, 2(1), 52-65.

Lai, C.-H., Yang, J.-C., Chen, F.-C., Ho, C.-W. \& Chant, T.-W. (2007) Affordances of Mobile Technologies for Experiential Learning: the interplay of technology and pedagogical devices, Journal of Computer Assisted Learning, 23(4), 326-337. http:/ / dx.doi.org/10.1111/j.1365-2729.2007.00237.x

Latour, B. (1987) Science in Action. Cambridge, MA: Harvard University Press.

Latour, B. (1999a) On Recalling ANT, in J. Law \& J. Hassard (Eds) Actor Network Theory and After, pp. 15-25. Oxford and Malden, MA: Blackwell.

Latour, B. (1999b) Factures/Fractures: from the concept of network to the concept of attachment, Res: Anthropology and Aesthetics, 36, 20-31.

Latour, B. (2005) Reassembling the Social. Oxford: Oxford University Press.

Latour, B. \& Woolgar, S. (1986) Laboratory Life: the construction of scientific facts, 2nd edn. Princeton, NJ: Princeton University Press.

Law, J. (1999) After ANT: complexity, naming and topology, in J. Law \& J. Hassard (Eds) Actor Network Theory and After, pp. 1-14. Oxford and Malden, MA: Blackwell.

Law, J. (2004) After Method: mess in social science research. London: Routledge.

Law, J. (2007) Actor-Network Theory and Material Semiotics. http:/ / www.heterogeneities.net/publications/Law2007ANTandMaterialSemiotics.pdf

McBride, N. (2003) Actor-Network Theory and the Adoption of Mobile Communications, Geography, 83(4), 266-276.

Motiwalla, L.F. (2007) Mobile Learning: a framework and evaluation, Computers \& Education, 49, 581-596. http: / / dx.doi.org/10.1016/j.compedu.2005.10.011

Murdoch, J. (1997) Towards a Geography of Heterogeneous Associations, Progress in Human Geography, 21(3), 321-337. http:/ / dx.doi.org/10.1191/030913297668007261

Naismith, L. \& Smith, M.P. (2009) Using Mobile Technologies for Multimedia Tours in a Traditional Museum Setting, in M. Ally (Ed.) Mobile Learning: transforming the delivery of education and training, pp. 247-264. Edmonton: AU Press.

Nyíri, K. (2002) Towards a Philosophy of M-Learning, in Proceedings of the IEEE International Workshop on Wireless and Mobile Technologies in Education. http: / / www.te.ugm.ac.id/ widyawan/mobilearn/M\%20learning\%20philosophy.pdf

Pachler, N. (2009) Mobile Learning: structures, agency, practices. New York: Springer.

Roschelle, J., Rosas, R. \& Nussbaum, M. (n.d.) Towards a Design Framework for Mobile ComputerSupported Collaborative Learning. http:/ / portal.acm.org/ citation.cfm?id=1149362

Sims Parr., C., Jones, T. \& Butler Songer, N. (2004) Evaluation of a Handheld Data Collection Interface for Science Learning, Journal of Science Education and Technology, 13(2), 233-242. http: / / dx.doi.org/10.1023/B:JOST.0000031262.22712.e0

Traxler, J. (2007) Defining, Discussing, and Evaluating Mobile Learning: the moving finger writes and having writ ..., International Review of Research in Open and Distance Learning, 8(2), 1-12.

Traxler, J. (2009) Current State of Mobile Learning, in M. Ally (Ed.) Mobile Learning: transforming the delivery of education and training, pp. 9-24. Edmonton: AU Press.

Tsirulnik, G. (2009) Smartphone Usage on the Rise: AdMob. http: / / www.mobilemarketer.com/cms/news/research/2900.html

Zurita, G. \& Nussbaum, M. (2004) A Constructivist Mobile Learning Environment Supported by a Wireless Handheld Network, Journal of Computer Assisted Learning, 20(4), 235-243.

http:/ / dx.doi.org/10.1111/j.1365-2729.2004.00089.x 
MATHIAS DECUYPERE is a PhD researcher at the Laboratory for Education and Society, Katholieke Universiteit Leuven, Belgium. His primary research interests are the changing nature of education policy, socio-technical approaches, the adoption of new media in education and higher education in particular. Correspondence: Mathias Decuypere, Laboratory for Education and Society, Katholieke Universiteit Leuven, Andreas Vesaliusstraat 2, Box 03761, B-3000 Leuven, Belgium (mathias.decuypere@ped.kuleuven.be).

MAARTEN SIMONS is Professor in the Center for Educational Policy and Innovation and the Laboratory for Education and Society, Katholieke Universiteit Leuven, Belgium. His research interests are in educational policy and political philosophy with special attention to governmentality and schooling, and the 'public' character of education. Correspondence: Maarten Simons, Center for Educational Policy and Innovation, Katholieke Universiteit Leuven, Andreas Vesaliusstraat 2, Box 03761, B-3000 Leuven, Belgium (maarten.simons@ped.kuleuven.be).

JAN MASSCHELEIN is Professor in the Laboratory for Education and Society, Katholieke Universiteit Leuven, Belgium. His primary areas of scholarship are educational theory, political philosophy, critical theory, studies of governmentality, and the 'public' character of education. Correspondence: Jan Masschelein, Laboratory for Education and Society, Katholieke Universiteit Leuven, Andreas Vesaliusstraat 2, Box 03761, B-3000 Leuven, Belgium (jan.masschelein@ped.kuleuven.be). 